\title{
THEEFFECT OF DIPEPTIDYL PEPTIDASE-4 INHIBITORS ON CARDIOVASCULAR DISEASE RISK IN TYPE 2 DIABETES MELLITUS
}

\author{
MARWA K. A. TOLBA ${ }^{1}$, KHALED A. EL KHASHAB ${ }^{2}$, AMIRA S. A. SAID ${ }^{3}$
}

${ }^{1}$ Hospital Pharmacy Department, Fayoum General Hospital, Fayoum, Egypt, ${ }^{2}$ Cardiology Department, Faculty of Medicine, Fayoum University, Fayoum, Egypt, ${ }^{3}$ Clinical Pharmacy Department, Faculty of Pharmacy, Beni-Suef University, Beni-Suef, Egypt

Email: drmarwa40@yahoo.com

Received: 01 Oct 2016 Revised and Accepted: 23 Nov 2016

\section{ABSTRACT}

Objective: The aim of this study was is to investigate the proposed beneficial cardiovascular effects of a novel class of antidiabetic drugs named; dipeptidyl peptidase 4 inhibitors. In this study, we compared the effect of using add-on therapy of vildagliptin (dipeptidyl peptidase-4 inhibitor; DPP-4i) and gliclazide (sulphonylurea; SU) to that when using gliclazide monotherapy in patients with type 2 diabetes mellitus (T2DM) and acute coronary syndrome (ACS) on different cardiovascular outcomes.

Methods: A total of 60 patients diagnosed with T2DM, and ACS were randomly recruited into two treatment groups each of 30 patients to receive either gliclazide monotherapy (SU) or vildagliptin (DPP4i)+gliclazide (SU) add-on therapy, administered in a double-blind fashion. Outpatient visits were scheduled at 3, 6, and 12 mo where patient was reevaluated for cardiovascular (CV) outcomes and followed up for any arising cardiovascular complication.

Results: The vildagliptin (DPP4i) plus gliclazide (SU) add-on therapy group have significantly shown more improved glycemic control, lipid profile and ventricular performance compared to gliclazide $(S U)$ monotherapy group with p values $<0.05$.

Conclusion: Vildagliptin as a DPP4i provides favourable cardiovascular effects beyond glucose control. Yet, its long-term safety and efficacy data still needs further investigations.

Keywords: Diabetes mellitus, Dipeptidyl peptidase-4 inhibitor, Cardiovascular disease

(c) 2017 The Authors. Published by Innovare Academic Sciences Pvt Ltd. This is an open access article under the CC BY license (http://creativecommons.org/licenses/by/4. 0/J DOI: http://dx.doi.org/10.22159/ijpps.2017v9i1.15496

\section{INTRODUCTION}

Cardiovascular disease (CVD) complications is considered fastest growing health concerns for many diabetic patients [1]. Type 2 diabetes mellitus (T2DM) doubles the risk of major cardiovascular complications for patients with or without established cardiovascular diseases [2-4], and causing up to $50-60 \%$ of T2DM patients death cases [5-8].

Accumulating evidence suggests that T2DM can negatively affect cardiovascular (CV) status by different pathogenic processes, which include accelerated atherosclerosis, as well as abnormalities in inflammatory pathways and in endothelial, myocardial, and platelet function [9-12]

Many antidiabetic agents such as metformin, sulfonylurea derivatives, and insulin have been found to improve glycemic control in T2DM significantly. However, none of them hardly had any favourable effect on cardiovascular complications associated with the disease such as dyslipidemia, hypertension, and obesity. On the other hand, many of these drugs even caused more harm than benefit to the cardiovascular (CVS) either by increasing weight gains such as insulin and sulphonylurea or by increasing CV risks such as thiazolidinedione $[13,14]$

Therefore, it has become a requirement by FDA that newly developed antidiabetic drugs' cardiovascular outcomes should be prioritized in clinical trials [15]. Consequently, the new focus for ideally developing an oral antidiabetic agent aimed not only to target a proper glycemic control in patients but also to improve CV outcomes. Therefore generally speaking it has been stressed that diabetes therapies with beneficial effects on glycemic control, vascular function and $\mathrm{CV}$ risks should be considered as more desirable future trends in T2DM treatment. A novel class of oral antihyperglycemic agents used to treat T2DM have been found promising in that respect named Dipeptidyl peptidase 4 (DPP4) inhibitors. These incretin-based drugs are GIT hormones that is released in response to nutrient ingestion. Incretins such as; glucagon-like peptide-1 (GLP-1) and glucose-dependent insulinotropic peptide (GIP) enhance glucose-dependent insulin secretion, suppresses glucagon secretion, which all contribute beneficially to the proper glycemic control. However, these actions are limited by their rapid inactivation in vivo by Dipeptidyl peptidase enzymes. Thus inhibition of these enzymes should prolong and enhance the activity of incretins that play a desirable role in insulin secretion and blood glucose control regulation [16]

Recently, Data have shown an increased expression of DPP-4 enzymes in visceral adipose tissue which raises the possibility about the pathophysiological role of these enzymes in diabetes development in obese patients [17]. In addition, DPP4i have been found to exert favourable cardiovascular effect mediated partially through specific receptors on cardiomyocytes, vascular endothelium and vascular smooth muscle cells [18]. Consequently, speculations have arisen that DPP4i might have a potential to reduce the cardiovascular diseases (CVD) burden among patients with T2DM. It has been postulated that using these drugs may offer a dual benefit of targeting proper glycemic control with CVS regulation and protection in T2DM patients.

Evidence from preclinical and small observational studies in humans showed that DPP4i have pleiotropic actions in T2DM patients resulting in favourable effects on postprandial glycemia, lipedema, blood pressure, silent inflammation, oxidative stress, and endothelial dysfunction $[19,20]$.

Thus regarding their anticipated favourable effects on several $\mathrm{CV}$ risk factors and mechanisms contributing to CV pathology, researchers now have become keener on investigating their actual potential to reduce $\mathrm{CV}$ events in T2DM. Contradicting, several other safety trials have shown that DPP-4i do not increase or decrease major adverse $\mathrm{CV}$ events over several years of use in individuals with T2DM and CV diseases [21]. 
As a matter of fact, the debate about DPP4i benefit in improving CV risks associated with T2DM, need more ongoing and future CV studies in order to provide the body of evidence needed to select these drugs for patients with T2DM optimally. Most studies in literature targeted investigating a specifically targeted CV event by comparing DPP4i with a placebo [22, 23]. However, researchers targeting comparison of DPP4i main CVS outcomes with other antidiabetic drugs remains few.

Thus our study aimed to compare between two treatment study groups; group 1 and 2 who received a monotherapy of a sulphonylurea named gliclazide (SU) or an add-on therapy of gliclazide plus vildagliptin (SU+DPP4i), respectively on different therapeutic outcomes such as glycated hemoglobin (HBA1c), fasting blood glucose level (FBG), lipid profile, body weight, and left ventricular ejection fraction (LVEF\%) in patients with type 2 diabetes mellitus and Acute coronary syndrome.

\section{MATERIALS AND METHODS}

\section{Study patients}

A total of 60 patients (31 males and 29 females) aged between 40-75, diagnosed with type 2 diabetes mellitus (T2DM), and had had a recent acute coronary syndrome (ACS) within 15 to $90 \mathrm{~d}$ were randomly recruited from intensive care unit at Fayoum general hospital. The study protocol was approved by the ethics committee of Fayoum general Hospital, Fayoum, Egypt (FM FU). All patients were asked to sign a consent form prior to participation in the study. Patients should have a confirmed history of T2DM proved by blood glucose and glycated haemoglobin test (HBA1c, 6.5 to $8.0 \%$ at screening). Selected patients should be hemodynamically stable and had a recent acute coronary syndrome (ACS) proved by the history of chest pain with evolving changes on the electrocardiogram; ST-segment elevation myocardial infarction (STEMI; anterior MI or inferior MI) or non-STsegment elevation myocardial infarction (NSTEMI) and positive troponin. Major exclusion criteria were a diagnosis of type 1 diabetes, history of ketoacidosis or requirements for insulin therapy within $1 \mathrm{y}$ of first diagnosis of diabetes, receiving DPP4i therapy for either more than $14 \mathrm{~d}$ total or within the past 3 mo prior to the study, unstable cardiac disorders (e. g., uncompensated heart failure, refractory angina,, or severe uncontrolled hypertension), kidney or liver diseases, pregnancy, and dialysis within $14 \mathrm{~d}$ before screening.

\section{Study drugs and procedures}

During ICU admission, all eligible patients received the standard conservative therapy for ACS (statin, aspirin, clopidogrel, heparin and nitrates) with standard doses according to the most updated guidelines [24]. Any patient contraindicated with any of the above drugs were excluded. The eligible patients' baseline demographic and clinical data were recorded after ICU discharge. Patients were subjected to a complete and detailed medical history, physical and clinical examination (ECG, Echo) and laboratory investigation (lipid profile, fasting blood glucose test and HbA1c). Informed consent was obtained from all individual participants included in the study.

After ICU discharge eligible diabetic patients with acute coronary syndrome (STEMI or NSTEMI) were randomly assigned into two treatment groups each of 30 patients to receive either gliclazide monotherapy (SU) or vildagliptin (DPP4i)+gliclazide (SU) add-on therapy, administered in a double-blind fashion till the end of the follow-up period.

Group 1 received an oral once or twice daily dose of $60 \mathrm{mg}$ gliclazide; a sulphonylurea monotherapy (diamicron ${ }^{\circledR}$ MR $60 \mathrm{mg}$; Servier, Egypt). Group 2 received an add-on therapy of an oral once or twice daily dose of $60 \mathrm{mg}$ gliclazide (SU) a sulphonylurea (diamicron ${ }^{\circledR}$ MR 60 tablets; Servier, Egypt) plus an oral once daily dose of vildagliptin; a DPP-4i (vildagluse $50 \mathrm{mg}$; Inspire pharma, Egypt). The once or twice daily dose of gliclazide was adjusted as needed to reach the HBA1c target level according to american society of endocrinologist guidelines $(\mathrm{HbA1C} \leq 6.5 \%)[25,26]$. Any therapeutic changes needed for the management of the patient's diabetes and ACS during the study was at the discretion of the responsible physician but with stressing that no concomitant DPP4i should be allowed.

Outpatient visits were scheduled at 3,6 , and 12 mo after randomization during the first year of the study. Patients of each treatment group were evaluated at these different time periods regarding glycated haemoglobin $(\mathrm{HbA1c})$, fasting blood glucose (FBG), lipid profile (LDL, HDL, TG, and weight) and echocardiography measurements (ejection fraction; $\mathrm{EF} \%$ ). All patients were followed up for any arising cardiovascular complication.

\section{Statistical analysis}

SPSS V18.0 (SPSS Inc, Chicago, USA) was used for statistical comparison of cardiovascular effects in type 2 diabetes mellitus patients when using a monotherapy of gliclazide (SU) or an add-on therapy of gliclazide (SU) plus vildagliptin (DPP4i). Comparison of the two treatment groups was accomplished using Paired t-test. The calculated P-value is considered significant if $\leq 0.05$.

\section{RESULTS}

A total of 60 randomly selected diabetic patients, registered in the intensive care unit at Beni-Suef general hospital as cases of acute coronary syndrome were recruited in the study and randomly assigned into two treatment groups. Group 1 of 30 patients (17 males and 13 females) with mean \pm SD age (year) and weight $(\mathrm{kg})$ of $56.9 \pm 6.1$, and $84.5 \pm 4.1$, respectively. Group 2 of 30 patients (14 males and 16 females) with mean $\pm S D$ (year) and weight $(\mathrm{kg})$ of $56.3 \pm 7,83 . \pm 75.1$ respectively. The two study treatment groups were well balanced with respect to baseline demographic and clinical characteristics or with respect to their smoking history and current medical condition as presented in table 1 .

Table 1: Baseline characteristics of the study patients $(n=60)$

\begin{tabular}{llll}
\hline Demographic details & & Group 1 (SU, n=30) & Group 2 (SU+DPP4i, n=30) \\
\hline mean \pm SD or No (\%) & & \\
\hline Age (y) & & $56.9 \pm 6.1$ & $56.3 \pm 7$ \\
Weight $(\mathrm{kg})$ & Male & $84.5 \pm 4.1$ & $83 . \pm 75.1$ \\
Sex & Female & $17 \pm 56.7 \%$ & $14 \pm 46.7 \%$ \\
& Smokers & $20 \pm 43.3 \%$ & $16 \pm 53.3 \%$ \\
Smoking & Non smokers & $10 \pm 33.3$ & $16 \pm 53.3$ \\
& Inferior MI & $14 \pm 46.7 \%$ & $14 \pm 46.7$ \\
ACS History & Anterior MI & $12 \pm 40 \%$ & $13 \pm 43.3 \%$ \\
& NSTEMI & $4 \pm 13.3 \%$ & $11 \pm 36.7 \%$ \\
Lipid profile (mg/dl) e & LDL & $132.9 \pm 9.6$ & $6 \pm 20 \%$ \\
& HDL & $36.2 \pm 4.4$ & $132.3 \pm 12.3$ \\
& TG & $180.03 \pm 10.3$ & $35.8 \pm 3.9$ \\
FBG (mg/dl) & & $173.6 \pm 8.7$ & $181.5 \pm 9.1$ \\
HBA1c $\%$ & & $7.7 \pm 0.27$ & $170.03 \pm 30.4$ \\
EF\% & $58.1 \pm 3.3$ & $7.8 \pm 0.27$ \\
\end{tabular}

SU; sulfonylurea, DPP4I; dipeptidyl peptidase 4 inhibitors, ACS; acute coronary syndrome, MI; myocardial infarction, NSTEMI; non ST segment elevation myocardial infarction, LDL; low density lipoprotein, HDL; low density lipoprotein, TG; triglyceride, FBG; fasting blood glucose, HBA1c; glycated hemoglobin, EF\%; ejection fraction \%. 
As shown fig. 1 and 2, the diabetic profile of patients in each study group showed a non-significant difference prior to treatment administration as regards to HBA1c and FBG. However, on the other hand, the glycemic profile regarding the same parameters differed significantly $(\mathrm{p}<0.05)$ after treatment for both groups. Notably, a more significant $(\mathrm{p}<0.05)$ reduction in HBA1c and FBG were found in group 2 receiving SU+DPP4i than in group 1 receiving the SU monotherapy. The mean \pm SD change from baseline in HBA1c and FBG post, one year of treatment, is $1.3 \pm 0.16,1.9 \pm 0.1 \%$, and $52.7 \pm 3.7,61.33 \pm 21.5 \mathrm{mg} / \mathrm{dl}$ for group $1(\mathrm{SU})$ and group 2 (SU+DPP4i), respectively.

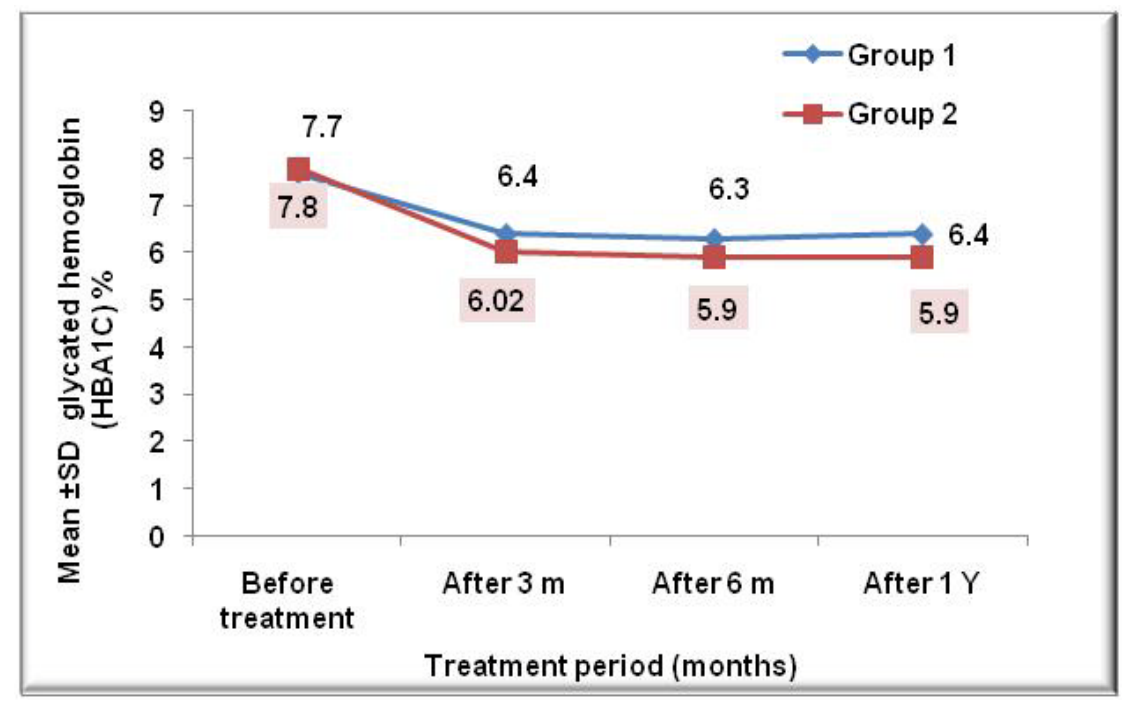

Fig. 1: Comparisons of HBA1c level follow-up in each study group

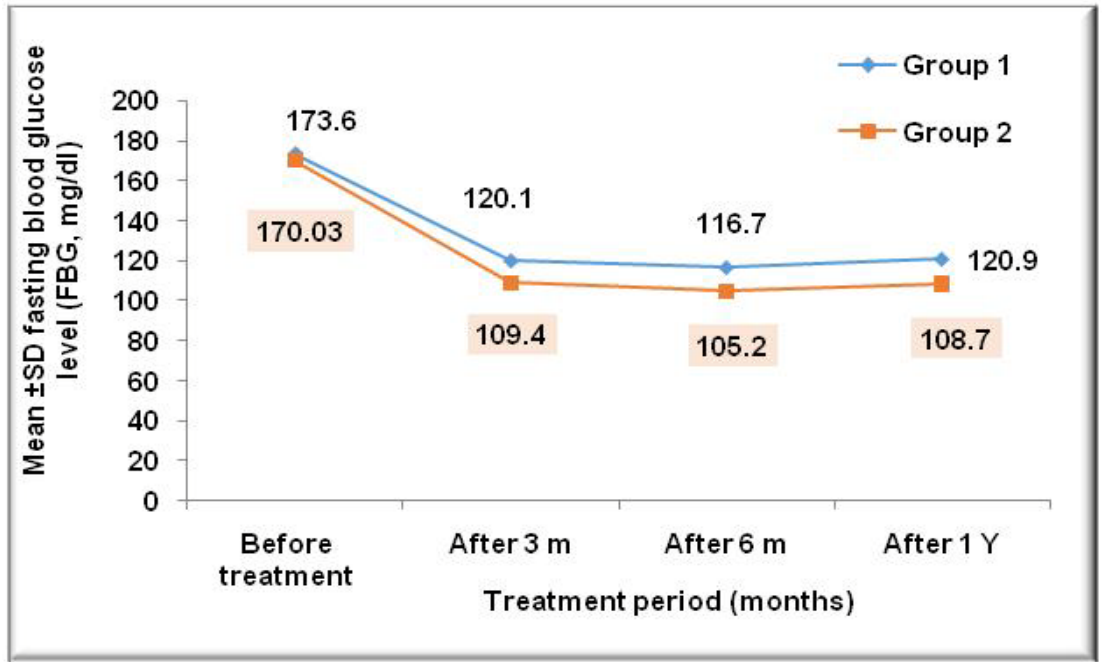

Fig. 2: Comparisons of FBS level follow-up in each study group

Similarly, as shown in the following table 2, the lipid profile of patients in both groups were non-significant prior to treatment. However, three and six months post-treatment group 2 (DPP4i+SU) showed more significant ( $\mathrm{p}<0.001)$ improvement regarding LDL, HDL and TG values.

Table 2: Mean lipid profile (HDL, LDL, TG) $\mathrm{mg} / \mathrm{dl}$ at baseline and post 3, 6 and $12 \mathrm{mo}$ of treatment $(\mathrm{n}=60)$

\begin{tabular}{|c|c|c|c|c|c|c|}
\hline \multirow[t]{2}{*}{ Mean \pm SD (mg/dl) } & \multicolumn{3}{|c|}{ Group $1(S U, n=30)$} & \multicolumn{3}{|c|}{ Group $2(S U+D P P 4 i, n=30)$} \\
\hline & LDL & HDL & TG & LDL & HDL & TG \\
\hline Pretreatment & $132.9 \pm 9.6$ & $36.2 \pm 4.5$ & $180.0 \pm 10.3$ & $132.3 \pm 12.3$ & $35.8 \pm 3.3$ & $181.5 \pm 9.1$ \\
\hline Post 3 mo & $90.03 \pm 5.5$ & $44.1 \pm 1.9$ & $136.2 \pm 3.9$ & $88 \pm 5.6$ & $46.9 \pm .2 .5$ & $132.3 \pm 5.6$ \\
\hline Post 6 mo & $89.2 \pm 5.5$ & $44.8 \pm 7.9$ & $133.8 \pm 6$ & $85.7 \pm 5.8$ & $48.5 \pm 3.1$ & $130 \pm 5.8$ \\
\hline
\end{tabular}

SU; sulfonylurea, DPP4i; dipeptidyl peptidase inhibitors, LDL; low-density lipoprotein, HDL; High-density lipoprotein, TG; triglyceride.

However, regarding LVEF\% of study patients, it was found that EF\% of group 2 was not significantly affected, whereas group $1 \mathrm{EF} \%$ showed a significant decline $(\mathrm{p}<0.001)$. The results were represented in fig. 3 . 


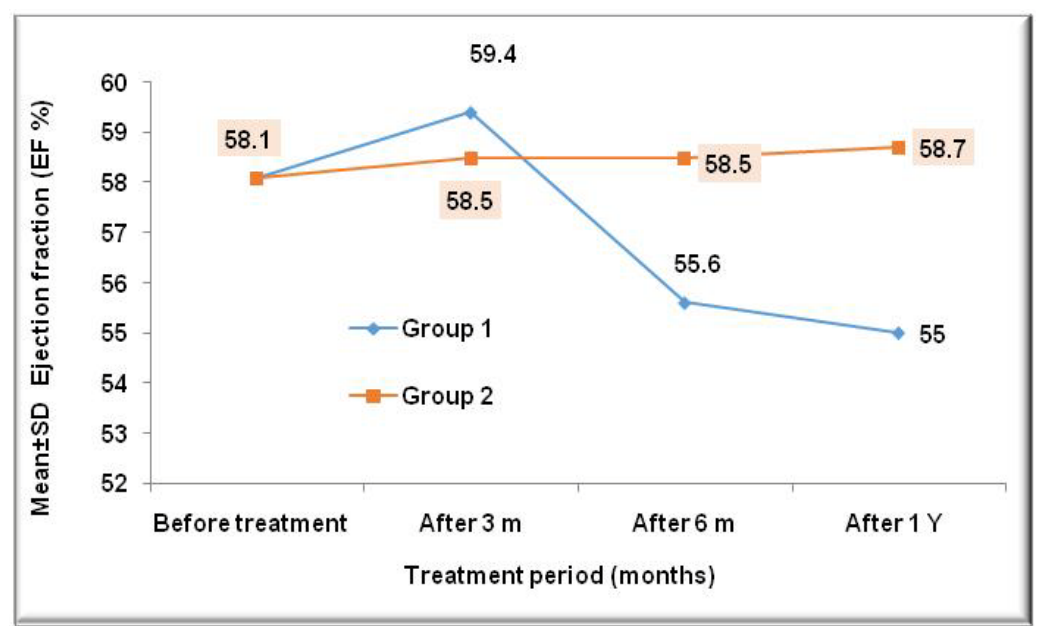

Fig. 3: Comparisons of EF\% follow-up in each study group

Regarding the effect of each treatment on patients' weight, group 1 patients (SU) weight significantly $(\mathrm{p}<0.01)$ increased from $82.5 \mathrm{~kg}$ pretreatment to $85.6 \mathrm{~kg}$, and $86.5 \mathrm{~kg}$ post 3 and 6 mo of treatment. However, On the other hand, group 2 patients (SU+DPP4i) weight were not affected by treatment. In addition, statistical comparison of patient's weight between both groups pre and post treatment were non-significant. Patients were also followed for any arising complications due to either treatment, however, as illustrated in table 3, it was found that both groups showed non-significance regarding Hospitalization and hypoglycemia incidences.

Table 3: No. (\%) percent incidence of hospitalization and hypoglycemia risk in study patients groups, (n=60)

\begin{tabular}{|c|c|c|}
\hline Risk incidence No. (\%) & Group $1(S U, n=30)$ & Group 2 (SU+DPP4i,n=30) \\
\hline \multicolumn{3}{|l|}{ Hospitalization } \\
\hline Post 6 mo & $5(16.7)$ & $2(6.7)$ \\
\hline \multicolumn{3}{|l|}{ Hypoglycemia } \\
\hline Post 3 mo & $1(3.3)$ & $2(6.7)$ \\
\hline Post 6 mo & $1(3.3)$ & $2(6.7)$ \\
\hline Risk incidence No. (\%) & Group $1(S U, n=30)$ & Group $2(S U+D P P 4 i, n=30)$ \\
\hline \multicolumn{3}{|l|}{ Re-hospitalization } \\
\hline Post 3 mo & $5(16.7 \%)$ & $2(6.7 \%)$ \\
\hline \multicolumn{3}{|l|}{ Hypoglycemia } \\
\hline Post 3 mo & $1(3.3 \%)$ & $2(6.7 \%)$ \\
\hline Post 6 mo & $1(3.3 \%)$ & $2(6.7 \%)$ \\
\hline Risk incidence No. (\%) & Group $1(S U, n=30)$ & Group $2(S U+D P P 4 i, n=30)$ \\
\hline \multicolumn{3}{|l|}{ Re-hospitalization } \\
\hline Post 3 mo & $5(16.7 \%)$ & $2(6.7 \%)$ \\
\hline \multicolumn{3}{|l|}{ Hypoglycemia } \\
\hline Post 3 mo & $1(3.3 \%)$ & $2(6.7 \%)$ \\
\hline Post 6 mo & $1(3.3 \%)$ & $2(6.7 \%)$ \\
\hline
\end{tabular}

SU; sulfonylurea, DPP4i; dipeptidyl peptidase inhibitors, All values are No. (\%)

As shown for the above table, only 5 (16.7) patients of group1 and 2 (6.7\%) patients of group 2 were hospitalised during the study period. Regarding hypoglycemia, both groups showed a similar number of patients showing hypoglycemic episodes.

\section{DISCUSSION}

Despite the fact that DPP-4 inhibitors (DPP4i) are widely spread in clinical use for the treatment of type 2 diabetes, however their cardiovascular safety has not been yet properly established. Thus more studies are still needed to clarify their effects on many cardiovascular events in diabetic patients. Patients with T2DM and recent acute coronary syndrome (ACS) selected for this study are considered the real candidate that should benefit from cardio protective effects of DPP4i if any.

The CVD risks associated with DPP4i treatment have been investigated in different studies but have shown many conflicting results. With DPP4i some studies showed an increased risk of MI and ischemic stroke [23, 27-29] or HF [22]. Contradictingly, other studies have shown a significantly lower HF risk [30] or a neutral effect on CV events [28].

Our study aimed to assess the cardiovascular outcomes associated with adding vildagliptin (DPP4i) to gliclazide (SU) versus gliclazide monotherapy in diabetic patients with acute coronary syndrome (ACS).
As shown from the above data using vildagliptin as add-on therapy to gliclazide caused a highly significant $(\mathrm{p}<0.001)$ reduction in HBA1c and FBG levels compared to gliclazide monotherapy. However, the beneficial effect of DPP4i addition on glycemic profile in this study was not at all surprising and comes in agreement with several previous studies [31]. Vildagliptin improved glycemia in T2DM patients have been reported when it was used as a monotherapy [32] as well as, a combination therapy with metformin [33], thiazolidinedione's [34], sulfonylureas [35] or insulin [36].

However, the issue here is not proving the improved glycemic control of diabetic patients using DPP4i which was confirmed by several studies, but the real debate is whether this glycemic improvement would have any pronounced effect regarding decreasing incidence of cardiovascular risks in those ACS diabetic patients.

Patients' lipid profile is considered a crucial factor that determines patients CV risks. 
As noted from our results the lipid parameters (HDL, LDL, and TG) significantly improved when vildagliptin therapy was added to gliclazide in group 2 at 3,6 , and 12 mo post treatment. This confirms the beneficial effects of vildagliptin add-on therapy on diabetic patients' lipid profile.

Similarly, a previous study by Matikainen et al., assessed the effects of vildagliptin on postprandial lipid and lipoprotein metabolism in diabetic patients and recorded an improvement in triglyceride metabolism following a fat-rich meal [37]. In addition, this is in accordance with several previous studies that also demonstrated a significant drop in triglyceride and LDL concentration post-DPP4i treatment [38, 39].

Several mechanisms, have been proposed to explain such beneficial effects on lipid profile by DPP4i other than improving glycemic control such as GLP-1 induced myocardial protection [40], improving endothelial function [41], and even having an antiinflammatory role by reducing C-reactive protein levels [42].

The above results gave researchers the hope that DPP4i might be the answer to resolving the common dyslipidemia concern in diabetic patients thus protecting them from subsequent CVD.

Pre and post patient's weight were not affected by vildagliptin plus gliclazide treatment. However, a significant increase was noted in patients' weight post-treatment with gliclazide monotherapy. However post-treatment weight results of both groups were nonsignificant. Although our results did not reach significance but SU group was more noted to increase patients' weight

This might be explained by the proposed enhanced postprandial lipid mobilisation and oxidation with vildagliptin, which is thought to decrease insulin resistance in T2DM patients as the otherwise accumulation of such lipid intermediates, may interfere with insulin signalling through receptors. Furthermore, such increased postprandial lipid oxidation could increase postprandial thermogenesis, thus explaining why vildagliptin does not lead to weight gain, as in the case with insulin, sulfonylurea, and thiazolidinedione therapy [43].

Over time, weight reduction may have an indirect benefit on cardiovascular risk, including blood pressure, cholesterol levels, inflammatory markers, and insulin resistance.

Regarding echo finding measurements (EF \%), our results have shown a significantly $(\mathrm{p}<0.05)$ improved Ejection fraction $(\mathrm{EF} \%)$ with group 2 (DPP4i+SU) than that observed with group 1 (SU) post different treatment periods.

The beneficial effect of $100 \mathrm{mg}$ sitagliptin on ejection fraction was previously confirmed by khan et al., 2010 who recorded an improved ejection fraction of $72.6 \pm 7.2 \%$ vs $63.9 \pm 7.9 \%, p=0.001$ compared to placebo in coronary heart diseases patients [40].

The first study to assess the effect of vildagliptin on ejection fractions in T2DM patients with left ventricular ejection fraction $[\mathrm{LVEF}]<40 \%$ has shown that vildagliptin increased the size of the left ventricle but without any decline in the its contraction and emptying which might speculate that this anti-diabetes drug may have improved the dispensability and compliance of the left ventricle [44].

Both groups of patients reported a similar incidence of hospitalisation and hypoglycemia. Although the non-significant difference in hypoglycemia demonstrated in this study, but several other studies have shown persistent fears from the tendency of insulin secretagogue such as the sulphonylurea groups to induce hypoglycemia that may impose additional myocardial ischemic risk in diabetic CAD patients. Consequently, SU drugs have been recommended to be used cautiously at the lowest effective dose, with ongoing regular glucose level monitoring for such patients [45]. Otherwise, DPP4i have been reported to have decreased the incidence of hypoglycemia which might be due to its effect on inhibiting glucagon levels during meal ingestion but sustaining glucagon counter-regulation during hypoglycemia. Thus vildagliptin may offer a potential add-on therapy for even T1DM patients without increasing the risk for hypoglycemia [46].

\section{CONCLUSION}

In conclusion, selection of the optimal antihyperglycemic agents in diabetes patients with cardiovascular complications pose many challenges to prescribers.

Our study has shown that the use of vildagliptin as a DPP4i plus gliclazide (SU) was not associated with increased CVD risks. Vildagliptin can be considered as a reasonably safe and effective medication option in T2DM with high CV risk. With comparable efficacy and more favourable $\mathrm{CV}$ outcomes, vildagliptin offers a more tailored approach to diabetes control in such a challenging group of patients.

\section{CONFLICT OF INTERESTS}

The authors state that they have no conflict of interest

\section{REFERENCES}

1. Sebokova E, Christ AD, Boehringer M, Mizrahi J. Dipeptidyl peptidase IV inhibitors: the next generation of new promising therapies for the management of type 2 diabetes. Curr Top Med Chem 2007;7:547-55.

2. Preis SR, Hwang SJ, Coady S, Pencina MJ, D'Agostino RB, Savage $\mathrm{PJ}$, et al. Trends in all-cause and cardiovascular disease mortality among women and men with and without diabetes mellitus in the Framingham Heart Study, 1950 to 2005. Circulation 2009;119:1728-35.

3. Bhatt DL, Eagle KA, Ohman EM, Hirsch AT, Goto S, Mahoney EM, et al. Comparative determinants of 4-year cardiovascular event rates in stable outpatients at risk of or with atherothrombosis. JAMA 2010;22:1350-7.

4. Emerging Risk Factors Collaboration. Diabetes mellitus, fasting blood glucose concentration, and risk of vascular disease: a collaborative meta-analysis of 102 prospective studies. Lancet 2010;375:2215-22.

5. Santulli G. Epidemiology of cardiovascular disease in the 21st century: updated numbers and updated facts. J Cardiovasc Dis 2013;1:1-2.

6. Turner LW, Nartey D, Stafford RS, Singh S, Alexander GC. Ambulatory treatment of type 2 diabetes in the US, 1997-2012. Diabetes Care 2014;1:985-92.

7. Reddy KJ, Mohan GK. The comparative antidiabetic activity of marketed gliclazide formulation with gliclazide loaded pellets containing gum kondagogu as a drug retarding material in rats. Asian J Pharm Clin Res 2013;6:73-5.

8. Dhaliwall C, Richardson J. Effectiveness of telephone-delivered interventions for increasing physical activity levels in persons with type 2 diabetes or hypertension: a systematic review. J Crit Rev 2015;19:6-11.

9. $\mathrm{Xu} \mathrm{J}$, Zou MH. Molecular insights and therapeutic targets for diabetic endothelial dysfunction. Circulation 2009;120:126686.

10. Wagenknecht LE, Zaccaro D, Espeland MA, Karter AJ, O'Leary DH, Haffner SM. Diabetes and progression of carotid atherosclerosis the insulin resistance atherosclerosis study. Arterioscler Thromb Vasc Biol 2003;23:1035-41.

11. Nathanson D, Nyström T. Hypoglycemic pharmacological treatment of type 2 diabetes: targeting the endothelium. Mol Cell Endocrinol 2009;297:112-26.

12. Avogaro A, Albiero M, Menegazzo L, de Kreutzenberg S, Fadini GP. Endothelial dysfunction in diabetes the role of preparatory mechanisms. Diabetes Care 2011;34:S285-90.

13. Simsek S, de Galan BE. Cardiovascular protective properties of incretin-based therapies in type 2 diabetes. Curr Opin Lipidol 2012;23:540-7.

14. Nissen SE, Wolski K. Effect of rosiglitazone on the risk of myocardial infarction and death from cardiovascular causes. New Eng J Med 2007;356:2457-71.

15. Nathan DM, Buse JB, Davidson MB, Ferrannini E, Holman RR, Sherwin R, Zinman B. Medical management of hyperglycemia in type 2 diabetes: a consensus algorithm for the initiation and adjustment of therapy a consensus statement of the American Diabetes Association and the European Association for the Study of Diabetes. Diabetes Care 2009;32:193-203. 
16. Green BD, Flatt PR, Bailey CJ. Dipeptidyl peptidase IV (DPP IV) inhibitors: a newly emerging drug class for the treatment of type 2 diabetes. Diab Vasc Dis Res 2006;3:159-65.

17. Lamers D, Famulla S, Wronkowitz N, Hartwig S, Lehr S, Ouwens $\mathrm{DM}$, et al. Dipeptidyl peptidase 4 is a novel adipokine potentially linking obesity to the metabolic syndrome. Diabetes 2011;60:1917-25.

18. Wei Y, Mojsov S. Tissue-specific expression of the human receptor for glucagon-like peptide-I: brain, heart and pancreatic forms have the same deduced amino acid sequences. FEBS letters 1995;358:219-24.

19. Kazakos K. Incretin effect: GLP-1, GIP, DPP4. Diabetes Res Clin Pr 2011;93:S32-6.

20. Ussher JR, Drucker DJ. Cardiovascular biology of the incretin system. Endocr Rev 2012 8;33:187-215.

21. Wu S, Hopper I, Skiba M, Krum H. Dipeptidyl Peptidase-4 Inhibitors and Cardiovascular Outcomes: Meta-Analysis of Randomized Clinical Trials with 55,141 Participants. Cardiovas Ther. 2014;32:147-58.

22. Scirica BM, Bhatt DL, Braunwald E, Steg PG, Davidson J, Hirshberg B, et al. Saxagliptin and cardiovascular outcomes in patients with type 2 diabetes mellitus. New Engl J Med 2013 3;369:1317-26.

23. White WB, Cannon CP, Heller SR, Nissen SE, Bergenstal RM, Bakris $\mathrm{GL}$, et al. Alogliptin after acute coronary syndrome in patients with type 2 diabetes. New Engl J Med 2013;369:1327-35.

24. Funnell MM, Brown TL, Childs BP, Haas LB, Hosey GM, Jensen B, et al. National standards for diabetes self-management education. Diabetes Care 2009;32:S87-94.

25. Mechanick JI, Youdim A, Jones DB, Garvey WT, Hurley DL, McMahon MM, et al. Clinical practice guidelines for the perioperative nutritional, metabolic, and nonsurgical support of the bariatric surgery patient-2013 update: cosponsored by American Association of Clinical Endocrinologists, the Obesity Society, and American Society for Metabolic and Bariatric Surgery. Obesity 2013;21:S1-27.

26. Inzucchi SE, Bergenstal RM, Buse JB, Diamant M, Ferrannini E, Nauck M, et al. Management of hyperglycemia in type 2 diabetes: a patient-centered approach position statement of the American Diabetes Association (ADA) and the European Association for the Study of Diabetes (EASD). Diabetes Care 2012;35:1364-79.

27. Green JB, Bethel MA, Armstrong PW, Buse JB, Engel SS, Garg J, et al. Effect of sitagliptin on cardiovascular outcomes in type 2 diabetes. New Eng J Med 2015;373:232-42.

28. Mogensen UM, Andersson C, Fosbøl EL, Schramm TK, Vaag A, Scheller NM, et al. Cardiovascular safety of combination therapies with incretin-based drugs and metformin compared with a combination of metformin and sulphonylurea in type 2 diabetes mellitus-a retrospective nationwide study. Diabetes Obes Metab 2014;16:1001-8.

29. Chang YC, Chuang LM, Lin JW, Chen ST, Lai MS, Chang CH. Cardiovascular risks associated with second-line oral antidiabetic agents added to metformin in patients with type 2 diabetes: a nationwide cohort study. Diabetic Med 2015;32: 1460-9.

30. Fadini GP, Avogaro A, Degli Esposti L, Russo P, Saragoni S, Buda $\mathrm{S}$, et al. Risk of hospitalisation for heart failure in patients with type 2 diabetes newly treated with DPP-4 inhibitors or other oral glucose-lowering medications: a retrospective registry study on 127,555 patients from the nationwide OsMed healthDB database. Eur Heart I 2015;36:2454-62.

31. ACCORD Study Group. Long-term effects of intensive glucose lowering on cardiovascular outcomes. $\mathrm{N}$ Engl J Med 2011;2011:818-28.
32. Scherbaum WA, Schweizer A, Mari A, Nilsson PM, Lalanne G, Jauffret $\mathrm{S}$, et al. Efficacy and tolerability of vildagliptin in drug-naïve patients with type 2 diabetes and mild hyperglycaemia. Diabetes Obes Metab 2008;10:675-82.

33. Ferrannini E, Fonseca V, Zinman B, Matthews D, Ahrén B, Byiers S, et al. Fifty-two-week efficacy and safety of vildagliptin vs. glimepiride in patients with type 2 diabetes mellitus inadequately controlled on metformin monotherapy. Diabetes Obes Metab 2009;11:157-66.

34. Rosenstock J, Kim SW, Baron MA, Camisasca RP, Cressier F, Couturier A, et al. Efficacy and tolerability of initial combination therapy with vildagliptin and pioglitazone compared with component monotherapy in patients with type 2 diabetes. Diabetes Obes Metab 2007;9:175-85.

35. Garber AJ, Foley JE, Banerji MA, Ebeling P, Gudbjörnsdottir S, Camisasca RP, et al. Effects of vildagliptin on glucose control in patients with type 2 diabetes inadequately controlled with a sulphonylurea. Diabetes Obes Metab 2008;10:1047-56.

36. Fonseca V, Schweizer A, Albrecht D, Baron MA, Chang I, Dejager S. Addition of vildagliptin to insulin improves glycaemic control in type 2 diabetes. Diabetologia 2007;50:1148-55.

37. Matikainen N, Mänttäri S, Schweizer A, Ulvestad A, Mills D, Dunning BE, et al. Vildagliptin therapy reduces postprandial intestinal triglyceride-rich lipoprotein particles in patients with type 2 diabetes. Diabetologia 2006;49:2049-57.

38. Bachovchin DA, Cravatt BF. The pharmacological landscape and therapeutic potential of serine hydrolases. Nat Rev Drug Discovery 2012;11:52-68.

39. Duvnjak L, Blaslov K. Dipeptidyl peptidase-4 inhibitors improve arterial stiffness, blood pressure, lipid profile and inflammation parameters in patients with type 2 diabetes mellitus. Diabetol Metab Syndr 2016;8:1.

40. Khan FZ, Heck PM, Hoole SP, Dutka DP. DPP-4 inhibition by sitagliptin improves the myocardial response to dobutamine stress and mitigates stunning in a pilot study of patients with coronary artery disease. Circulation: Cardiovascular Imaging 2010;3:195-201.

41. Takasawa W, Ohnuma K, Hatano R, Endo Y, Dang NH, Morimoto C. Inhibition of dipeptidyl peptidase 4 regulates microvascular endothelial growth induced by inflammatory cytokines. Biochem Biophys Res Commun 2010;401:7-12.

42. Wu JD, Xu XH, Zhu J, Ding B, Du TX, Gao G, et al. Effect of exenatide on inflammatory and oxidative stress markers in patients with type 2 diabetes mellitus. Diabetes Technol Ther 2011;13:143-8.

43. Boschmann M, Engeli S, Dobberstein K, Budziarek P, Strauss A, Boehnke J, et al. Dipeptidyl-peptidase-IV inhibition augments postprandial lipid mobilization and oxidation in type 2 diabetic patients. J Clin Endocrinol Metab 2009;94:846-52.

44. Scheen AJ. A review of gliptins in 2011. Expert Opin Pharmacother 2012;13:81-99.

45. Inzucchi SE, McGuire DK. New drugs for the treatment of diabetes part II: incretin-based therapy and beyond. Circulation 2008;117:574-84.

46. Farngren J, Persson M, Schweizer A, Foley JE, Ahrén B. Vildagliptin reduces glucagon during hyperglycemia and sustains glucagon counter regulation during hypoglycemia in type 1 diabetes. J Clin Endocrinol Metab 2012;97:3799-8.

\section{How to cite this article}

- Marwa KA Tolba, Khaled A EL Khashab, Amira SA Said. The effect of dipeptidyl peptidase-4 inhibitors on cardiovascular disease risk in type 2 diabetes mellitus. Int J Pharm Pharm Sci 2017;9(1):254-259. 